Methods Study population was drawn from the KompNet HIV cohort. Inclusion criteria were: age $\geq 18$ years, record of HIV diagnosis date $(\mathrm{t} 0)$, record of $\mathrm{CD} 4$ count available \pm 6 months from $\mathrm{t} 0$. Patients without month of HZ diagnoses were excluded. Study period was 1.1.1985-1.7.2010.

Incidences of all $\mathrm{HZ}$ events were estimated assuming Poisson distribution, uni-/multivariate Cox proportional Hazard ratio (HR) regression models were fitted to identify risk factors for a first $\mathrm{HZ}$ event. Independent variables were: sex, age at HIV diagnosis, HIV transmission route, ART status, CD4-value before $\mathrm{HZ}$ episode, immunosuppressive medication, mode of data documentation (retrospective/prospective).

Results Study population comprised 3,757 subjects (86\% male, $66 \%$ MSM, 3\% IVDU, 92\% Caucasian), mean age at HIV diagnosis was 38 years, mean observation time was 5.8 years.

$362 \mathrm{HZ}$ events were recorded in 326 patients (8.6\%), resulting in an $\mathrm{HZ}$ incidence of 16.7/1,000 PY overall and 16.1/1,000 PY for first $\mathrm{HZ}$ cases. Main risk factors associated with first $\mathrm{HZ}$ event were: no ART compared to an ART containing a non-nucleoside reverse-transcriptase inhibitor (NNRTI vs no ART; HR 0.530, $\mathrm{p}<0.001$ ) or a protease inhibitor (PI vs no ART; HR 0.624, $\mathrm{p}=0.004$ ), lower CD4-cell count (rise 100 cells/ $\mu \mathrm{l}$, HR 0.918, $\mathrm{p}=0.001$ ) and retrospective data documentation (HR 0.582, $p<0.001)$. No risk factors were: sex, age, HIV transmission route, immunosuppressive medication.

Conclusions According to former studies incidence of HZ in HIVinfected individuals was $\sim 5$ times higher than in the general population. Our study showed ART as important protective associated factor for $\mathrm{HZ}$ events. Reasons may be earlier HIV-diagnosis, more recent picturing of ART, and low IVDU proportion in our study.

\section{P2.121 EARLY PRESENTATIONS OF KAPOSI'S SARCOMA IN HIV- INFECTED PERSONS WHICH WERE UNAWARE OF THEIR STATUS}

doi:10.1136/sextrans-2013-051184.0385

G Mavrov. Institute for Dermatology and Venereology of Ukraine, Kharkiv, Ukraine

Introduction and Objectives Kaposi's sarcoma (KS) may be the first clinical indicator of AIDS; nevertheless there are no studies of KS features concerning HIV in Ukraine. So the aim was to study epidemiological and clinical peculiarities of KS in HIV-infected persons.

Materials \& methods We were studying 176 HIV-positive patients with various skin manifestations: 90 females and 86 males aged 18-71 (mean 28.8 8.7 ) years. Serological status (New Low Blot - Bio-Radium) and clinical stage of the infection (CD3, CD4, CD8, CD16, and CD20 count - Becton Dickinson - USA) were determined according to WHO guidelines (2006).

Results Kaposi's sarcoma was determined in 27 (15.3\%) patients: $13(7.3 \%)$ patients with Kaposi's sarcoma were classified to be at clinical stage 3 of HIV infection, and 14 (8.0\%) patients - at stage 4 . The lesions were localised on the face, neck, mouth, hand and legs. Skin biopsies were compatible with Kaposi's sarcoma. The CD4 count was 200-350 cells $/ \mathrm{mm}^{3}$. None of 27 patients with Kaposi's sarcoma knew about his or her HIV status. They first visited dermatologist or cosmetologist. Some of them underwent cosmetic procedures (tattoo, piercing) during last five years. All of them had one another dermatosis or more: seborrhea (16 patients), mycosis (9), and herpes or papilloma virus infections (9). Patients were receiving ARV therapy and were on regular clinic surveillance.

Conclusions Kaposi's sarcoma lesions are often observed in untreated unaware immunocompromised HIV-infected patients, and may be the first clinical manifestation of AIDS. Clinical features of Kaposi's sarcoma should be the choice of the first examination in dermatological practise.

\section{P2.122 HIV IS AN INDEPENDENT PREDICTOR OF AORTIC PULSE WAVE VELOCITY}

doi:10.1136/sextrans-2013-051184.0386

${ }^{1}$ E C Wainwright, ${ }^{2} \mathrm{O}$ J Rider, ${ }^{2} \mathrm{M}$ Asaad, ${ }^{2} \mathrm{~N}$ Ntusi, ${ }^{2} \mathrm{G}$ Hancock, ${ }^{2} \mathrm{~A}$ Pitcher, ${ }^{2} \mathrm{~K}$ Clarke, ${ }^{2} \mathrm{~L}$ Dorrell, ${ }^{2} \mathrm{~S}$ Neubauer, ${ }^{2} \mathrm{C}$ Holloway. ${ }^{1}$ Oxford University Hospitals NHS Trust, Oxford, UK; ${ }^{2}$ Oxford University, Oxford, UK

Background Patients with HIV infection are at increased risk of cardiovascular events. Many potential causes have been proposed, including immunodeficiency, chronic immune activation and traditional cardiovascular risk factors. However, metabolic and anthropometric abnormalities associated with HIV and antiretroviral therapy are likely to play an important role in cardiovascular disease development. These metabolic abnormalities are similar to the metabolic syndrome (MS), an established risk factor for cardiovascular mortality.

This study aimed to investigate the relationship between HIV infection and a surrogate measure of cardiovascular risk and compare this to the risk associated with metabolic syndrome.

Methods 90 patients with HIV and 113 without HIV underwent magnetic resonance imaging to determine aortic pulse wave velocity (PWV), a clinical measure of aortic stiffness, predictive of cardiovascular mortality. Subjects were divided into 4 groups: (1) HIV-ve/ MS-ve, (2) HIV-ve/MS+ve, (3) HIV+ve/MS-ve and (4)HIV+ve/ MS+ve.

Results Aortic PWV was 16\% higher in the HIV+ve/MS-ve group when compared to HIV-ve/MS-ve $(6.2 \pm 1.9$ vs $5.4 \pm 1.0 \mathrm{~m} / \mathrm{s}, \mathrm{p}=0.008)$ and similar to that observed in the HIV-ve/MS+ve group (6.2 \pm 1.9 vs $6.3 \pm 1.7 \mathrm{~m} / \mathrm{s}, \mathrm{p}>0.99)$. The HIV+ve/MS+ve group had $38 \%$ higher PWV than HIV-ve/MS-ve group $(p<0.001)$ and 19\% higher PWV than HIV+ve/MS-ve subjects $(p=0.049)$. On multivariable regression age $(b=0.07, p<0.001)$, systolic blood pressure $(b=0.02$, $\mathrm{p}=0.02)$ and treated HIV infection $(b=0.62, p=0.01)$ were all independent predictors of aortic PWV (overall R2 $=0.34, p<0.001$ ). Conclusion Treated HIV infection is associated with increased aortic stiffness. The magnitude of this effect of treated HIV is similar to that observed with the metabolic syndrome. Furthermore HIV and MS are additive in their detrimental effects on vascular function.

\section{P2.123 OCULAR MANIFESTATIONS DURING HIV INFECTION IN BUKAVU, D.R.CONGO}

doi:10.1136/sextrans-2013-051184.0387

'B D Ngoma, ${ }^{2} \mathrm{~N}$ A Bulabula, ' $\mathrm{C}$ P Katoto, ${ }^{1} \mathrm{~A}$ B Bamuleke, ${ }^{1} \mathrm{C}$ M Mweze. ${ }^{1}$ Provincial General Hospital Of Bukavu, Drc, Catholic University of Bukavu, Bukavu, Congo; 2Provincial General Hospital of Bukavu, Drc, Bukavu, Congo

Background In our area, there are little data about ocular manifestations of HIV infection. This study aims to determine the prevalence of these manifestations in Bukavu, D.R.Congo.

Methods We conducted a prospective study in three large hospitals in the city of Bukavu in South Kivu, Eastern Democratic Republic of Congo, including the Provincial General Hospital of Bukavu, Panzi General Referral Hospital and General Referral Hospital of Kadutu, from March 2012 to February 2013. All HIV-positive patients with an available CD4 count were examined at the ophthalmology unit, we included from them, patients without refractive error.

Results Of 80 patients examined, 71 were selected including 49 women (69\%) and 22 men (31\%). 